\section{Some New Anthocyanin Types}

A WIDE survey of anthocyanins occurring in the angiosperms (and a few gymnosperms) has revealed the overwhelming predominance of pigments based on pelargonidin, cyanidin and delphinidin and methyl ethers of the last two. The only exceptional cases are the nitrogenous anthocyanins, typified by the beet colouring matter, gesnerin from flowers of Gesnera fulgens, which is the sole representative of the flavylium class related to flavones rather than to flavonols, and certain yellow pigments such as those of Papaver nudicaule and Celosia cristata aurea.

The colouring matter of the yellow Iceland poppy has been isolated; it is nitrogenous, and will be described elsewhere. That of the yellow Cristata resembles it in some respects, but differs in others; it is doubtful whether either is a flavylium salt.

We have recently found that the red colour of certain young fern fronds (the coloration soon disappears) is due to entirely new anthocyanins in some cases; in others the familiar pigments have been identified.

Among the Pteridophyta examined we may mention Davallia divaricata as containing mixed pelargonidin and cyanidin dimonosides in an acylated form. This shows that normal anthocyanins may occur in the cryptogams.

The new types occur in Osmunda regalis var. Hillii, and $O$. palustris, Didymochloena truncatula, Pteris aspericaulis, Blechnum brasiliense, Dryopteris varia, Adiantum Vietchianum and Polypodium rhodoleuron.

The anthocyanins include monoglycosides and diglycosides; the anthocyanidins, of which at least three kinds have been recognized, are not identical with any known polyhydroxyflavylium salts. They resemble, however, 6-hydroxypelargonidin and 6hydroxycyanidin.

\section{J. R. PRICE.}

Violet C. Sturgess.

John Innes Horticultural Institution, Merton Park, London, S.W.19.

R. RobINSON.

Gertrude M. Robinson.

Dyson Perrins Laboratory, Oxford.

Aug. 2.

\section{By-products in Aromatic Nitration}

IT was known fifty years ago that hydroxy byproducts arise in small quantities in the nitration of benzene and toluene, and their significance was discussed by Armstrong and Rossiter in 1891. Since that time little has been added to the subject apart from a number of observations of the increased production of such by-products in the presence of mercuric salts.

We have now found that, in the nitration of aromatic compounds with meta-directive groups, hydroxy by-products are formed in considerable quantity: in the nitration of nitrobenzene, for example, styphnic acid is produced in amounts vary. ing from 0.5 to 6.5 per cent according to the conditions.

The process appears to involve the direct introduction of a hydroxyl group in the meta position, followed by complete tri-nitration (directed by the hydroxyl group). The resulting substance then either appears as such-for example, hexanitro-3:3'. dihydroxybenzophenone formed in the nitration of benzophenone; or the original directive group, now subject to the influence of three nitro-groups, is displaced by hydroxyl, and styphnic acid is isolatedas for example in nitrating nitrobenzene, phenyl methyl sulphone or diphenyl sulphone.

\section{G. M. BennetT. \\ P. V. Youle.}

The University,

Sheffield.

Quantitative Measurement of Vitamin $B_{1}$ and its Phosphoric Esters and their Synthesis in Animal Tissues

Recently, in Nature, Westenbrink and Goudsmit ${ }^{1}$ described estimations of the vitamin $B_{1}$ and cocarboxylase content of animal tissues, based upon the observation that thiochrome phospho-esters do not pass into a butyl alcohol layer ${ }^{2}$.

In results described to the Biochemical Society on May 5, $1938^{3}$, and embodied in a paper just sent to press, we have given estimations of these two forms of vitamin $B_{1}$ by different methods in rat and pigeon tissues. Our methods of estimation are based upon the use of yeast enzymes, and are in some sense complementary to those of the above authors, because the cocarboxylase as estimated by us can only be the diphospho-ester, whereas in their method it is possible that the mono-ester is also included; on the other hand, our method does not distinguish between vitamin $B_{1}$ and its monophospho-ester. It is interesting that our main conclusion was substantially the same, that there is more cocarboxylase than vitamin $B_{1}$ in most tissues, though muscle in our experiments contains relatively more of the latter. We also found that vitamin $B_{1}$ injected into the avitaminous animals is rapidly taken up by the liver, giving an accumulation of both forms of the vitamin; differing from them, however, slightly increased amounts of free aneurin were found in brain and muscle soon after injection. It will be interesting if the points of difference are due to the presence of the mono. phospho-ester.

We may add that (as already mentioned to the Biochemical Society) liver slices produce cocarboxylase from vitamin $B_{1}$. Liver slices or 'brei' may convert 25-30 per cent of the vitamin into cocarboxylase in 30 minutes at $38^{\circ}$. The synthetic reaction has a markedly alkaline $p \mathrm{H}$ optimum (about 8.5 ) ; it is inhibited by iodoacetic acid $(0.0009 \mathrm{~mol}$.) and little affected by fluoride $(0.04 \mathrm{~mol}$.) or by addition of phosphoglyceric acid and adenylpyrophosphate, whether separately or together. Other tissues show either a very limited activity (brain, muscle) or none at all (intestinal mucosa); kidney tissue has not so far been investigated by us. We have recently found that the synthetic reaction can also be obtained with liver extracts; this is being further investigated.

\section{S. OCHOA. \\ R. A. Peters.}

Department of Biochemistry, Oxford.

July 23.

1 Westenbrink, H. G. K., and Goudsmit, J., NATURE, 142, 151 (1938). 'Kinnersley, H. W., and Peters, R. A., J. Soc. Chem. Ind., 58, 447 (1937).

S Ochoa, S., and Peters, R. A., J. Soc. Chem. Ind., 57, 470 (1938). See also, Ochoa, S., NATURE, 148, 831 (1938). 